\title{
MULTI-OBJECTIVE OPTIMIZATION ON THE BASIS BY RATIO ANALYSIS METHOD SEBAGAI SISTEM PENDUKUNG KEPUTUSAN PENERIMAAN ASISTEN LABORATORIUM (STUDI KASUS PRODI TEKNIK SIPIL UNIVERSITAS PGRI SEMARANG)
}

\author{
Setyoningsih Wibowo', Slamet Budirahardjo² \\ ${ }^{1}$ Fakultas Teknik dan Informatika, Universitas PGRI Semarang, email : \\ setyoningsihwibowo@upgris.ac.id \\ ${ }^{2}$ Fakultas Teknik dan Informatika,Universitas PGRI Semarang, email : \\ slametbudiraharjo@upgris.ac.id
}

\section{ARTICLE INFO}

Article history:

Received : 22 April 2019

Received in revised form : 01 July 2019

Accepted : 25 july 2019

Available online : 31 July 2019
ABSTRACT

Decision support system is a system used to assist problem solving and decision-making. MOORA (Multi-Objective Optimization by Ratio Analysis) is a decision support system that involves complex calculations and selective assessments of the alternatives. Recruitment of laboratory assistant is a serious issue because a number of factors need to be considered and decided. A laboratory assistant helps the head of laboratory and lecturer during a practicum, provides maintenance for and takes care of laboratory equipment, as well as keeps the cleanliness of the laboratory room. Until today, laboratory assistant recruitment is conducted through the process of interview and written test followed by a manual selection. In this study, the researcher uses the cases frequently occurring in the Department of Civil Engineering in order to recruit laboratory assistants objectively. The process in MOORA method used as a decision support system shows that such method is appropriate to be implemented in the Department of Civil Engineering because the outcome matches the target with an objective assessment as expected. This selection is only applied in one practicum course while the other courses can conduct a similar recruitment process accordingly. The study results in a list of ranked candidates, allowing the laboratory head to decide which candidate becomes the recruited assistant based on the highest score obtained. The MOORA method provides a solution for the decision to select the candidates based on their scores, and the result shows that the recruited laboratory assistant for Laboratory A1 is M. Ilham Fauzi with a score of 0.767 for the Road Paving course. As a follow-up, such system can be applied in all the faculties, particularly in each of the department in Universitas PGRI Semarang for the recruitment of laboratory assistant.

Keywords: smarsofi, social wifi, digital marketing 


\section{Pendahuluan}

Dalam penerimaan asisten laboratorium menjadi masalah penting dimana banyak faktor yang harus dipertimbangkan dan diputuskan. Pada penelitian ini kami mengambil contoh kasus yang sering dialami oleh Program Studi Teknik Sipil. Adalah salah satu prodi di Lingkungan Fakultas Teknik dan Informatika (FTI) Universitas PGRI Semarang (UPGRIS). Program studi ini berdiri pada tahun 2014 dengan jumlah mahasiswa yang masih sedikit, dengan berjalannya waktu, tahun demi tahun program studi ini semakin banyak peminatnya. Dengan semakin banyaknya mahasiswa, kepala laboratorium dan dosen pengampu mata kuliah merasa sangat membutuhkan asisten laboratorium guna membantu pelaksanaan praktikum. Disini dosen mempunyai masalah dalam menentukan asisten laboratorium. Asisten laboratorium bertugas membantu kepala laboratorium dan dosen pengampu dalam proses pelaksanaan praktikum, menjaga dan merawat peralatan serta menjaga kebersihan laboratorium. Selama ini penerimaan asisten laboratorium dilakukan dengan wawancara dan ujian tertulis kemudian baru dilakukan seleksi penilaian secara manual.

Sistem yang dirancang yang digunakan untuk mendukung manajemen didalam suatu pengambilan keputusan disebut dengan sistem pendukung keputusan. Banyak metode sistem pendukung keputusan yang digunakan dalam penerimaan asisten laboratorium, pemilihan karyawan terbaik, guru teladan dan lain sebagainya. Beberapa metode tersebut antara lain Analytic Hierarchy Process (AHP), Simple Additive Weighting (SAW), Weighted Product (WP), Technique Order Preference by Similarity to Ideal Solution (TOPSIS), Multi-Objective Optimization by Ratio Analysis (MOORA).

Penelitian tentang pemilihan asisten laboratorium yang dilakukan oleh Lia [1] menggunakan metode Simple Additive Weighting (SAW) dalam penelitian ini, peneliti membandingkan hasil akhir perhitungan secara statistic dan menggunakan metode SAW. Hasil yang didapatkan berdasarkan pengujian data, data pelatihan dan data pengujian memiliki akurasi $90 \%$. Menggunakan sembilan kriteria yang telah ditetapkan dan membuat peringkat dari perolehan skor yang tertinggi. Dengan system ini membantu perkuliahan dan forum asisten untuk memilih asisten laboratorium.

Penelitian yang dilakukan oleh Sri Wardani dkk [2] tentang pemilihan supplier untuk mendapatkan bahan baku yang efektif dan efisien sehingga membantu Toko Megah Gracindo Jaya dalam membuat sebuah keputusan sebagai upaya mendapatkan keuntungan. Pada penelitian ini metode moora digunakan untuk menentukan nilai pembobotan.

Penelitian Kimberly [3] bagaimana menentukan area pemasaran yang strategis, karena saat ini dengan hadirnya pesaing di lokasi pemasaran sangat mempengaruhi daya saing produk sehingga pelaku bisnis harus benar-benar melakukan perhitungan yang menjadi dasar pemilihan lokasi pemasaran yang strategis, dimana pelaku bisnis masing-masing mempunyai kreteria yang berbeda. Dengan menggunakan metode MOORA peneliti menggunakan 6 lokasi sebagai bahan perhitungan. Hasil yang didapatkan dari penelitian ini pelaku bisnis dapat lebih efektif dan obyektif dalam membuat suatu keputusan

Menurut Rokhman metode MOORA (Multi-Objective Optimization by Ratio Analysis) adalah salah satu metode sistem pendukung keputusan dimana metode ini memperhitungkan kalkulasi yang kompleks dan dalam penentuan alternatifpun sangat selektif [4]. Dibandingkan metode yang telah disebutkan diatas, MOORA lebih fleksible pengaplikasiannya, hasil lebih akurat dan tepat sasaran [5].

Sehubungan dengan masalah pemilihan asisten laboratorium peneliti membangun aplikasi Multi-Objective Optimization on the basis by Ratio Analysis Method sebagai Sistem Pendukung Keputusan Penerimaan Asisten Laboratorium pada Program Studi Teknik Sipil Fakultas Teknik dan Informatika Universitas PGRI Semarang.

TRANSFORMATIKA Vol. 17, No. 1, July 2019: 49-56 


\section{Metodologi}

Banyak penelitian yang membahas tentang penerapan ataupun implementasi dari penggunaan metode ini. antara lain Hidayatullah dkk dalam penelitiannya Metode Moora Dengan Pendekatan Price-Quality Ratio Untuk Rekomendasi Pemilihan Smartphone menghasilkan rekomendasi peringkat smartphone yang paling hemat (pemeringkatan didasarkan pada seberapa efisien nilai uang terhadap kualitas smartphone yang didapatkan) namun bukan smartphone dengan kualitas terbaik [6]. Penelitian Wardani, dkk tentang bagaimana menganalisa menggunakan moora dalam pemilihan supplier pada toko bahan bangunan yang menghasilkan perhitungan dalam penentuan bobot [3]. Perbedaan dari kedua penelitian diatas dengan penelitian ini adalah metode MOORA diterapkan dalam bidang akademisi yang sebagai proses penerimaan asisten laboratorium.

\section{Sistem Pendukung Keputusan}

Sistem Pendukung Keputusan diperkenalkan oleh Turban [7], beliau mendefinisikan bahwa sistem yang berbasis computer interaktif sangat membantu dalam pengambilan suatu keputusan dimana data dan model sebagai pemecah masalah yang tidak terstruktur dengan kata lain memadukan sumber daya intelektual individu dengan komputer yang berkapasitas dalam menentukan tingkat keputusan.

Menurut Alter [8] sistem ini adalah sistem informasi yang interaktif menyediakan informasi, model dan manipulasi data, yang digunakan untuk membantu pengambilan suatu keputusan semi struktur dan tidak terstruktur, sebagaimana keputusan seharusnya diputuskan. Dimana keputusan adalah aktifitas menseleksi menggunakan strategi atau tindakan untuk memecahkan suatu masalah dengan tujuan untuk mencapai target yang harus dilakukan. Kriteria atau alternative, misalnya banyaknya alternative yang digunakan, persyaratan khusus, mengikuti aturan suatu pola, baik yang terstruktur maupun tidak, banyaknya variable, faktor resiko dan yang terakhir dibutuhkan kecepatan, ketepatan dan akurat.

Hasan [9] mengatakan bahwa keputusan adalah akhir dari proses pemikiran suatu masalah, bagaimana mencari solusi untuk menjawab masalah tersebut dengan menentukan alternative. Sedangkan Umar [10] memberikan pendapat bahwa pada dasarnya pengambilan keputusan adalah suatu proses mekanisme dalam pemilihan berbagai alternative dengan tujuan hasil keputusan yang didapatkan adalah keputusan yang terbaik.

\section{Metode MOORA}

Suatu metode baru diusulkan untuk optimalisasi multi-objektif dengan alternatif diskrit: MOORA (Multi-Objective Optimization berdasarkan Analisis Rasio). Metode MOORA diperkenalkan oleh Brauers dkk mengawali menggunaan tersebut dalam pengambilan keputusan yang bersifat multikriteria [11]. Metode ini mengacu pada matriks tanggapan alternatif terhadap tujuan, dimana rasionya telah diterapkan. selanjutnya, ditunjukkan pilihan terbaik di antara metodemetode yang bersaing lainnya. Dalam MOORA, penyetingan rasio memiliki akar kuadrat dari jumlah respon kuadrat sebagai penyebut. Rasio tak berdimensi ini, terletak antara nilai nol dan satu, untuk kasus maksimalisasi ditambahkan atau sebagai kasus minimalisasi dikurangi. Akhirnya, semua alternatif diberi peringkat, sesuai dengan rasio yang diperoleh.

Metode MOORA memiliki beberapa fleksibilitas dan kemudahan pemahaman karena membagi bagian subjektif dari proses penilaian menjadi kriteria penimbangan keputusan dengan beberapa atribut pengambilan keputusan [5]. Metode ini dapat menentukan tujuan kriteria yang bertentangan karena memiliki tingkat selektivitas yang sangat baik. Di mana standar mungkin berharga atau bermanfaat.

Multi-Objective Optimization On the Basis By Ratio Analysis Method Sebagai Sistem Pendukung Keputusan Penerimaan Asisten Laboratorium(Studi Kasus Progdi Teknik Sipil Universitas PGRI 
Metode MOORA diterapkan untuk menyelesaikan banyak masalah ekonomi, administratif, dan konstruktif di perusahaan atau proyek. Metode ini memiliki tingkat selektivitas yang sangat baik ketika memilih alternatif. Pendekatan MOORA didefinisikan sebagai proses mengoptimalkan secara simultan dua atau lebih kriteria yang bertentangan untuk kendala tertentu [12].

\section{Definisi Metode MOORA}

$X=\left|\begin{array}{llll}X_{11} & X_{12} & \ldots & X_{1 n} \\ X_{21} & X_{22} & \ldots & X_{2 n} \\ X_{m 1} & X_{m 2} & \ldots & X_{m n}\end{array}\right|$

di mana $\mathrm{x}_{\mathrm{ij}}$ adalah respons dari alternatif $\mathrm{j}$ terhadap objektif $\mathrm{i}, \mathrm{i}=1,2, \ldots, \mathrm{n}$ adalah tujuan, sedangkan $\mathrm{j}=1,2, \ldots \mathrm{m}$ adalah alternatifnya.

$$
N x_{i j}=\frac{x_{i j}}{\sqrt{\sum_{j=1}^{m} X_{i j}^{2}}}
$$

Dengan:

$\mathrm{x}_{\mathrm{ij}}=$ respons alternatif $\mathrm{j}$ terhadap objektif $\mathrm{i} . \mathrm{j}=1,2, \ldots \mathrm{m} ; \mathrm{m}$ nomornya alternatif, $\mathrm{i}=1,2, \ldots \mathrm{n}$; dalam jumlah tujuan,

$N x_{i j}=$ angka tanpa dimensi yang mewakili respons normal dari alternatif $\mathrm{j}$ ke tujuan $\mathrm{i}$; ini tanggapan normal dari alternatif untuk tujuan termasuk interval $[0 ; 1]$.

Untuk optimisasi, respons ini ditambahkan jika maksimalisasi dan dikurangi jika terjadi minimalisasi:

$N y_{i j}=\sum_{i=1}^{i=g} N x_{i j}-\sum_{i=g+1}^{i=n} N x_{i j}$

Dengan:

$\mathrm{i}=1,2, \ldots, \mathrm{g}$ untuk tujuan yang akan dimaksimalkan, $\mathrm{i}=\mathrm{g}+1, \mathrm{~g}+2, \ldots, \mathrm{n}$ untuk tujuan yang harus diminimalkan,

$N y_{j}=$ penilaian normalisasi alternatif $\mathrm{j}$ sehubungan dengan semua tujuan. Dalam formula ini, linearitas menyangkut pengukuran tanpa dimensi dalam interval $[0 ; 1]$. Peringkat ordinal $N y_{j}$ menunjukkan preferensi akhir.

Teori titik referensi dimulai dari rasio yang sudah dinormalisasi seperti yang didefinisikan dalam metode MOORA, yaitu rumus (2).

Selanjutnya, teori titik referensi memilih untuk memaksimalkan titik referensi, yang telah mengoordinasikan koordinasi tertinggi per sasaran semua kandidat alternatif. Untuk minimalisasi, koordinat terendah dipilih.

$\operatorname{Min}\left\{\max \left|r_{i}-N x_{i j}\right|\right\}$

dimana:

$\mathrm{i}=1,2, \ldots \mathrm{n}$ adalah tujuannya, $\mathrm{j}=1,2, \ldots, \mathrm{m}$ adalah alternatifnya,

$r_{i}=$ koordinat ke-i dari titik referensi objektif maksimal; setiap koordinat titik referensi dipilih sebagai koordinat tertinggi yang sesuai alternatif,

TRANSFORMATIKA Vol. 17, No. 1, July 2019: 49-56 
$N x_{i j}=$ tujuan normalisasi i dari alternatif $\mathrm{j}$.

\section{Metode Penelitian}

Dalam riset ini mengimplementasikan bagaimana penggunaan metode moora sebagai sistem pendukung keputusan dalam hal ini sebagai seleksi pemilihan asisten laboratorium. Gambar 1. menunjukkan diagram alir dari metode penelitian yang dilakukan. Pada awal proses dilakukan menentukan kriteria terlebih dahulu. Kriteria yang digunakan adalah nilai mata kuliah, nilai IPK, kejujuran, attitude dan kedisiplinan. Setelah itu kita tentukan nilai bobot prosentase dan nilai bobot masing-masing kriteria. Nilai bobot prosentase pada nilai mata kuliah adalah 25\%, nilai IPK 25\%, kejujuran $20 \%$, attitude $15 \%$ dan kedisplinan $15 \%$. Sedangkan untuk penilaian kriteria dengan bobot Sangat Baik adalah 5, Baik adalah 4, Cukup adalah 3, Kurang adalah 2.

Penyelesaian dari metode moora adalah menginput nilai kriteria pada suatu alternatif, merubah nilai kriteria menjadi matrik keputusan kemudian menormalisasi agar matrik memiliki nilai yang seragam selanjutnya mengurangi nilai maksimal dan minimalnya, yang terakhir menentukan ranking dari hasil perhitungan metode moora.

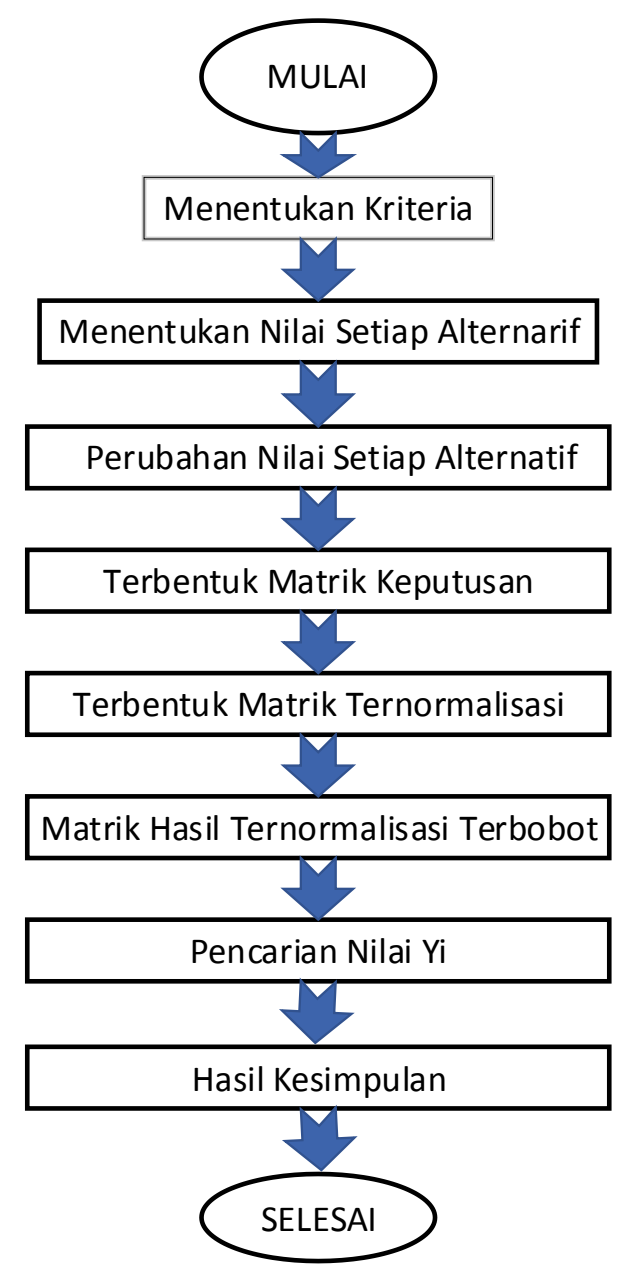

Gambar 1. Metode Penelitian 


\section{Hasil}

Terlihat pada Tabel 1 memperlihatkan kriteria yang menjadi penilaian pada penerimaan asisten laboratorium. Dalam tabel terdapat 5 (lima) kriteria, sedangkan calon asisten laboratorium ada 10 (sepuluh) mahasiswa pelamar.

Tabel 1. Kriteria penilaian

\begin{tabular}{clc}
\hline Kriteria & \multicolumn{1}{c}{ Keterangan } & Jenis \\
\hline $\mathrm{C} 1$ & Nilai Mata Kuliah & benefit \\
\hline $\mathrm{C} 2$ & IPK & benefit \\
\hline $\mathrm{C} 3$ & Kejujuran & benefit \\
\hline $\mathrm{C} 4$ & Attitude & benefit \\
\hline $\mathrm{C} 5$ & Kedisiplinan & benefit \\
\hline
\end{tabular}

Dibawah ini pada Tabel 2 adalah hasil dari nilai rata-rata wawancara dan ujian tertulis.

Tabel 2. Hasil Nilai Seleksi

\begin{tabular}{|c|c|c|c|c|c|}
\hline Alternatif & $\mathrm{C} 1$ & $\mathrm{C} 2$ & $\mathrm{C} 3$ & $\mathrm{C} 4$ & $\mathrm{C} 5$ \\
\hline A1 & Sangat Baik & Sangat Baik & Sangat Baik & Baik & Sangat Baik \\
\hline $\mathrm{A} 2$ & Baik & Baik & Baik & Baik & Sangat Baik \\
\hline A3 & Cukup & Baik & Baik & Sangat Baik & Sangat Baik \\
\hline $\mathrm{A} 4$ & Baik & Baik & Sangat Baik & Baik & Baik \\
\hline A5 & Baik & Cukup & Baik & Cukup & Baik \\
\hline A6 & Baik & Sangat Baik & Sangat Baik & Baik & Baik \\
\hline A7 & Baik & Baik & Baik & Baik & Cukup \\
\hline A8 & Cukup & Cukup & Baik & Baik & Sangat Baik \\
\hline A9 & Cukup & Baik & Baik & Baik & Baik \\
\hline A10 & Baik & Baik & Cukup & Cukup & Cukup \\
\hline
\end{tabular}

Setelah didapatkan nilai rata-rata dari hasil wawancara dan ujian tertulis hasil seleksi dengan kriteria penilaian yang telah ditetapkan, langkah selanjutnya adalah dengan membuat matrik normalisasi kemudian dilakukan pembobotan. Maka pada Tabel 4. sebagai nilai hasil pengurangan maksimal dan minimal untuk mendapatkan nilai Yi nya, dan pada Tabel 5 adalah nilai kesimpulan atau nilai keputusan yang dihasilkan.

Tabel 4. Pencarian nilai Yi

\begin{tabular}{cccc}
\hline Alternatif & $\begin{array}{c}\text { Max } \\
(\mathrm{C} 1+\mathrm{C} 2+\mathrm{C} 3+\mathrm{C} 4+\mathrm{C} 5)\end{array}$ & Min $(0)$ & Yi $=$ Max - Min \\
\hline $\mathrm{A} 1$ & 0,767 & 0 & 0,767 \\
\hline $\mathrm{A} 2$ & 0,656 & 0 & 0,656 \\
\hline $\mathrm{A} 3$ & 0,639 & 0 & 0,639 \\
\hline $\mathrm{A} 4$ & 0,663 & 0 & 0,663 \\
\hline
\end{tabular}

TRANSFORMATIKA Vol. 17, No. 1, July 2019: 49-56 


\begin{tabular}{cccc} 
A5 & 0,569 & 0 & 0,569 \\
\hline A6 & 0,703 & 0 & 0,703 \\
\hline A7 & 0,609 & 0 & 0,609 \\
\hline A8 & 0,575 & 0 & 0,575 \\
\hline A9 & 0,592 & 0 & 0,592 \\
\hline A10 & 0,554 & 0 & 0,554 \\
\hline
\end{tabular}

Tabel 5. Hasil Kesimpulan

\begin{tabular}{ccc}
\hline Alternatif & Yi = Max - Min & Ranking \\
\hline A1 & 0,767 & 1 \\
\hline A2 & 0,656 & 4 \\
\hline A3 & 0,639 & 5 \\
\hline A4 & 0,663 & 3 \\
\hline A5 & 0,569 & 9 \\
\hline A6 & 0,703 & 2 \\
\hline A7 & 0,609 & 6 \\
\hline A8 & 0,575 & 8 \\
\hline A9 & 0,592 & 7 \\
\hline A10 & 0,554 & 10 \\
\hline
\end{tabular}

Tabel 6. Final Report

\begin{tabular}{ccc}
\hline Alternatif & Yi $=$ Max - Min & Ranking \\
\hline M. Ilham Fauzi & 0,767 & 1 \\
\hline Wisnu Saputra & 0,703 & 2 \\
\hline Asy Syakur & 0,663 & 3 \\
\hline Fristi Manda A. A & 0,656 & 4 \\
\hline Didik Purnomo & 0,639 & 5 \\
\hline Anggie B. N & 0,609 & 6 \\
\hline Nafis Nurchamim & 0,592 & 7 \\
\hline Dania Ayu S & 0,575 & 8 \\
\hline Fatah Halim & 0,569 & 9 \\
\hline Fajar Ikhsanul F & 0,554 & 10
\end{tabular}

Penentuan penilaian yang baik, tentu harus melakukan analisis dari berbagai kriteria penilaian. Kepala laboratorium akan mengambil beberapa opsi penilaian yang dianggap sangat berpengaruh selama melaksanakan tugas sebagai asisten laboratorium. Maka kriteria penilaian yang digunakan sebagai referensi juga harus ditetapkan. Beberapa kriteria yang digunakan menghasilkan keputusan yang efektif dan efisien sehingga keputusan yang didapatkan sesuai dengan apa yang diharapkan. Dengan menerapkan metode MOORA ini memberikan solusi terbaik serta upaya dalam mendapatkan keputusan yang terbaik. 
Ringkasan terakhir pada Tabel 6 memperlihatkan hasil peringkatan sesuai ranking, maka kepala laboratorium dapat menentukan siapa yang terpilih sebagai asisten laboratorium sesuai dengan peringkat tertinggi.

Metode MOORA memberikan solusi keputusan dengan menetapkan nilai yang tertinggilah yang dijadikan hasil akhirnya, sehingga calon asisten laboratorium A1 atas nama M. Ilham Fauzi dengan nilai 0.767 yang terpilih sebagai asisten laboratorium mata kuliah Perkerasan Jalan.

\section{Kesimpulan}

Dari rangkaian proses metode MOORA yang digunakan sebagai sistem pendukung keputusan dalam penerimaan asisten laboratorium disimpulkan bahwa metode ini sangat cocok diimplementasikan pada Prodi Teknik Sipil karena hasil keluaran sesuai dengan target yang diharapkan dengan penilaian secara obyektif dan sesuai dengan yang diharapkan. Seleksi ini diberlakukan hanya untuk satu mata kuliah praktikum, maka untuk mata kuliah praktikum yang lain dilakukan seleksi sesuai dengan calon asisten yang melamar pada mata kuliah tersebut. Sebagai tindak lanjut kedepan sistem ini dapat diterapkan untuk semua fakultas khususnya masing-masing program studi di Lingkungan Universitas PGRI Semarang sebagai sistem dalam sebuah seleksi.

\section{Referensi}

[1]. Lia A. I, Ema U dan Emha T. L, Sistem Pendukung Keputusan Seleksi Penerimaan Calon Asisten Praktikum, Jurnal Ilmiah DASI Desember 2015, Vol. 16 No. 4, hal 37-46.

[2]. Wardani, S, Parlina, I, Revi, A [4], Analisis Perhitungan Metode Moora Dalam Pemilihan Supplier Bahan Bangunan Di Toko Megah Gracindo Jaya, Jurnal Nasional Informatika dan Teknologi Jaringan, September 2018Vol 3, No 1, hal 95-99.

[3]. Kimberly F. K, S Supiyandi dan M. Mesran, Application of Multi-Objective Optimization on The Basis of Ratio Analysis (MOORA) in Strategic Location Marketing, International Journal Of Scientific Research In Science And Technology (IJSRST), 2018, Volume 4, Issue 2.

[4]. Rokhman, I. F. Rozi, and R. A. Asmara, "Pengembangan Sistem Penunjang Keputusan Penentuan UKT Mahasiswa Dengan Menggunakan Metode MOORA Studi Kasus Politeknik Negeri Malang,” J. Inform. Polinema, 2017, Vol. 3, pp. 36-42.

[5]. Mandal, K. U., dan Sarkar, B., Selection of Best Intelligent Manufacturing System (IMS) Under Fuzzy Moora Conflicting MCDM Environment, International Journal of Emerging Technology and Advanced Engineering, 2012, Vol.2, No.9.

[6]. Hidayatulloh, I, Naf'an, M.Z Metode Moora Dengan Pendekatan Price-Quality Ratio Untuk Rekomendasi Pemilihan Smartphone, Proceeding SINTAK, 2017, hal 62-68.

[7]. Turban, Efraim, dkk., Decision Support and Intelligent System, Edisi 7, Yogyakarta: Andi, 2005.

[8]. Kusrini, Konsep dan Aplikasi Sistem Pendukung Keputusan, Yogyakarta : Andi Offset, 2007.

[9]. Hasan, M. Iqbal, , Pokok-pokok Materi Teori Pengambilan Keputusan, Bogor: Ghalia Indonesia, 2004.

[10]. Umar, Husein, Metode Penelitian dan Aplikasi dalam Pemasaran, Jakarta: PT Gramedia Pustaka Umum, 2001.

[11]. Brauers, W.K.M., dan Zavadskas, E.K. 2006. The MOORA Method And Its Application To Privatization In A Transition Economy. Control and Cybernetics, No.2, Vol.35, 445-469.

[12]. Attri R, Grover S Decision Making Over the Production System Life Cycle: MOORA Method. 2013, International Journal of System Assurance Engineering Management 5(3), pp. 320328.

TRANSFORMATIKA Vol. 17, No. 1, July 2019: 49-56 